\title{
Symptomatic snapping knee from biceps femoris tendon subluxation: an unusual case of lateral pain in a marathon runner
}

\author{
Giovanni Vavalle $\cdot$ Michele Capozzi
}

Received: 27 February 2010/Accepted: 21 October 2010/Published online: 3 December 2010

(C) The Author(s) 2010. This article is published with open access at Springerlink.com

\begin{abstract}
Snapping biceps femoris syndrome is an uncommon cause of lateral knee pain and may be difficult to diagnose, resulting in unsuccessful surgical intervention. In this report, we present an unusual case of a 37-year-old male marathon runner with unilateral snapping knee secondary to dislocation of the long head of the biceps femoris over the fibular head during knee flexion. The pain was great enough to interfere with his ability to practice sport. Possible causes of symptomatic snapping knee include multiple intra-articular or extra-articular pathology. Biceps femoris snapping over the fibular head is a rare condition. Reported causes include an anomalous insertion of the tendon into the tibia, trauma, and fibular-head abnormality. However, none of those conditions accounted for his symptoms. Failing conservative treatment, the patient underwent surgery for partial resection of the fibular head, with subsequent sudden resolution of symptoms and return to sport. Accurate knowledge and management of this rare condition is mandatory to avoid inappropriate therapy and unnecessary surgical procedures.
\end{abstract}

Keywords Snapping knee - Biceps femoris subluxation · Marathon runner

G. Vavalle $\cdot$ M. Capozzi

Department of Orthopaedics, Saint Mary Hospital,

De Ferrariis 18/D, Bari 70124, Italy

G. Vavalle $(\square)$

Via Martiri della Giustizia, 9, Noicattaro 70016, Italy

e-mail: gvavalle@libero.it

\section{Introduction}

Painful snapping knee is an uncommon syndrome secondary to several different conditions, such as meniscal pathology, synovial plicae, iliotibial syndrome, and patellar dysplasia. Clinical reports of lateral knee pain caused by tendon subluxation have seldom been reported in the literature. We describe a rare case of knee pain secondary to subluxation of the long head of the biceps femoris over the fibular head in an athlete who showed no evident anatomic abnormalities. Failing conservative treatment, the patient underwent partial resection of the fibular head, with subsequent symptom resolution at the final clinical evaluation.

\section{Case report}

A 37-year-old male marathon runner presented with a 3-year history of pain-free snapping of left knee during strenuous cycling and running. Over the previous 2 years, the onset of lateral pain had increasingly limited his activities, forcing him to retire from active sport. No clear traumatic history was reported, and no symptoms were present in the contralateral knee. On physical examination, a snap was evident over the fibular head, accompanied by pain with knee range of motion from $120^{\circ}$ to $100^{\circ}$, with tibia internally rotated, and with displacement of the long head of the biceps femoris muscle. Manual compression of the distal biceps eliminated the snapping. Meniscal pathology, ligamentous stability, axial alignment, and active and passive range of motion were normal (Fig. 1a, b).

The fibular head did not appear remarkably prominent on either knee. Routine radiographs and magnetic resonance imaging (MRI) were normal (Fig. 2). 
Fig. 1 Preoperatively: normal axial alignment of the lower limb and no evident anatomic abnormalities of the knee in the anterior (a) and lateral (b) views
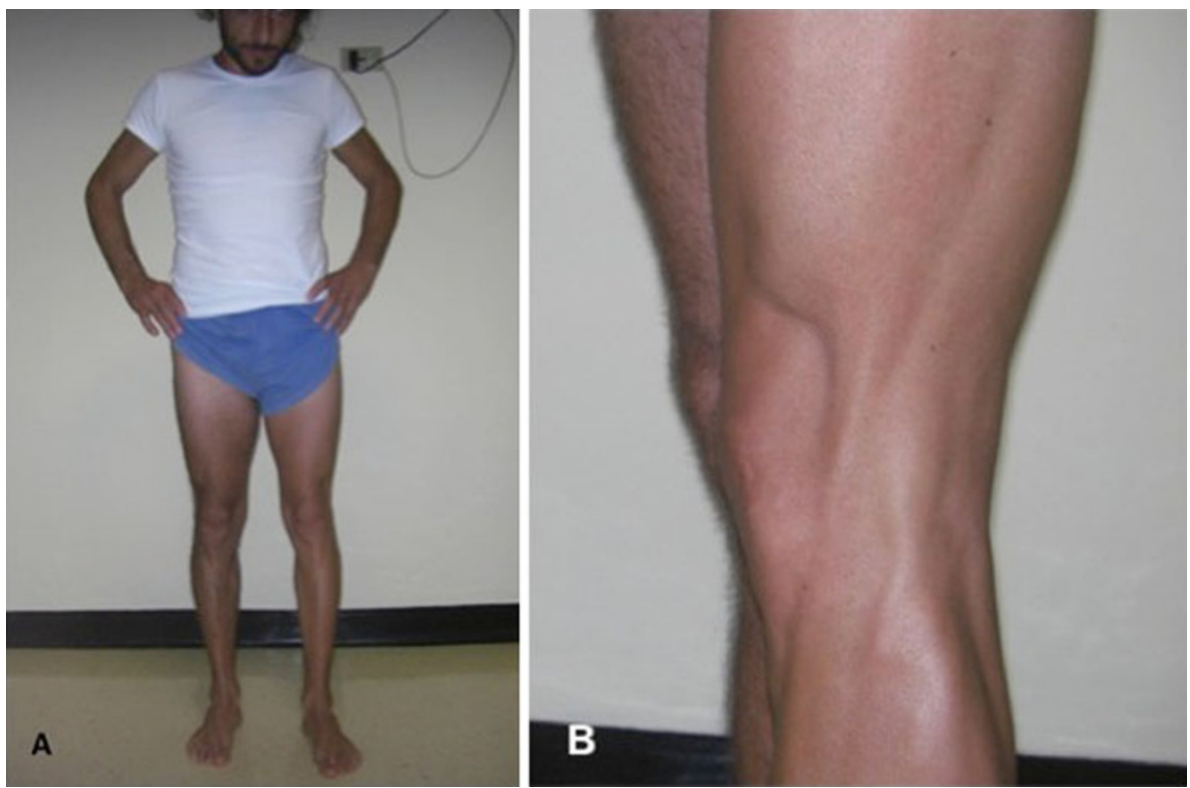

Conservative treatment with rest, anti-inflammatory medications, and hamstring stretching was unsuccessful. He was diagnosed with snapping biceps femoris syndrome and was scheduled for operative exploration. The surgical procedure was performed under combined spinal anesthesia (CSA) without motor block, permitting active knee movement upon request. As noted, at clinical examination, when the tourniquet was placed around the thigh and inflated, tendon subluxation could not be reproduced. A 4-in. longitudinal incision was performed over the fibular head, and the tendon and the common peroneal nerve were isolated (Fig. 3). The diagnosis was confirmed, as the biceps femoris tendon subluxated over the fibular head during knee extension from $120^{\circ}$ to $100^{\circ}$ with internal rotation.
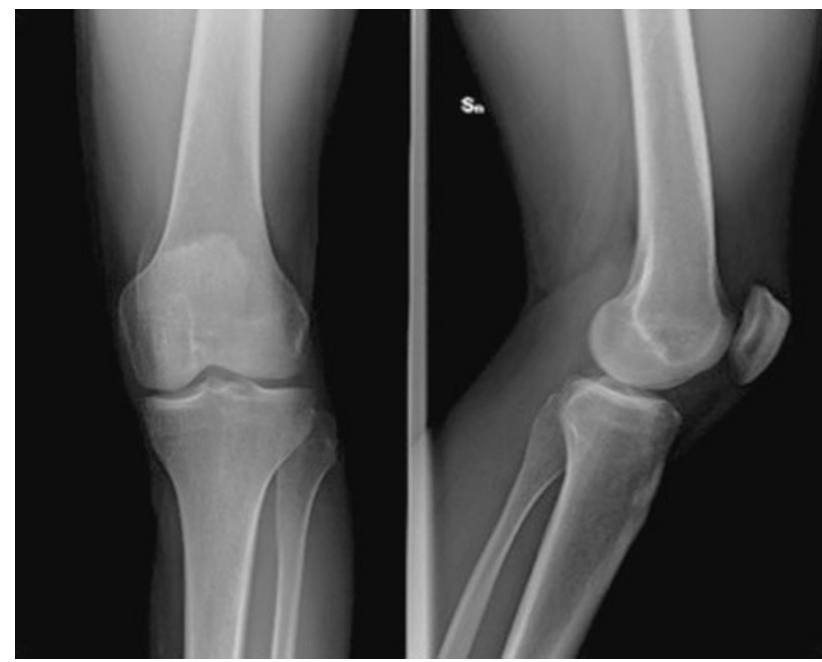

Fig. 2 Preoperative anterior and lateral weightbearing radiograph of the left knee revealed no osseous abnormalities
The tendon was inserted normally, with no anatomic anomaly on the anterior portion of the fibular head; however, the tendon subluxated on the superior and posterior portions. We partially resected the posterior portion of the fibular head (Fig. 4) without supplementary procedure on the tendon. Snapping resolved when the knee was passively moved in flexion-extension. Sufficient bone resection was confirmed when the patient moved his knee, with no evidence of tendon subluxation.

The patient was discharged the following day and was permitted early motion and progression to full weight bearing, as tolerated, within a few days. After 10 days, a rehabilitation program was started, including range of motion, strengthening, and stretching exercises. The patient was immediately asymptomatic and returned to all sport activities after 2 months.

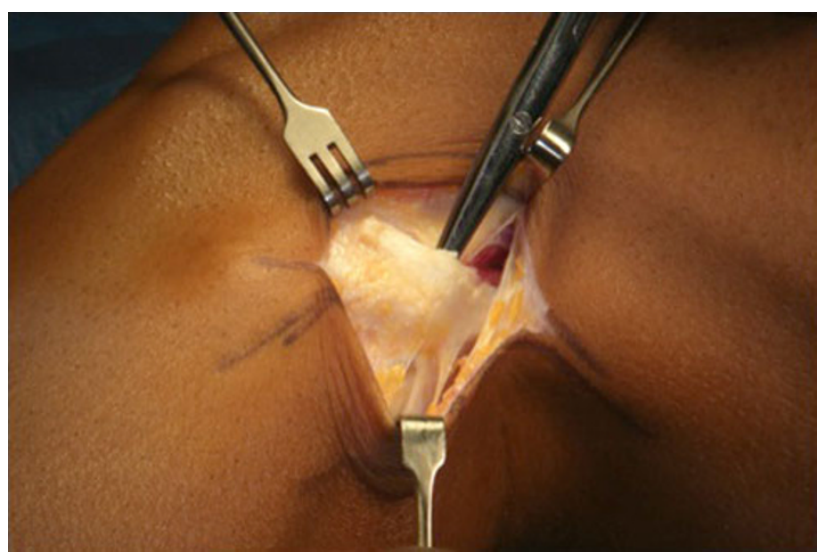

Fig. 3 Partial release of the superior portion of the long head of the biceps femoris 


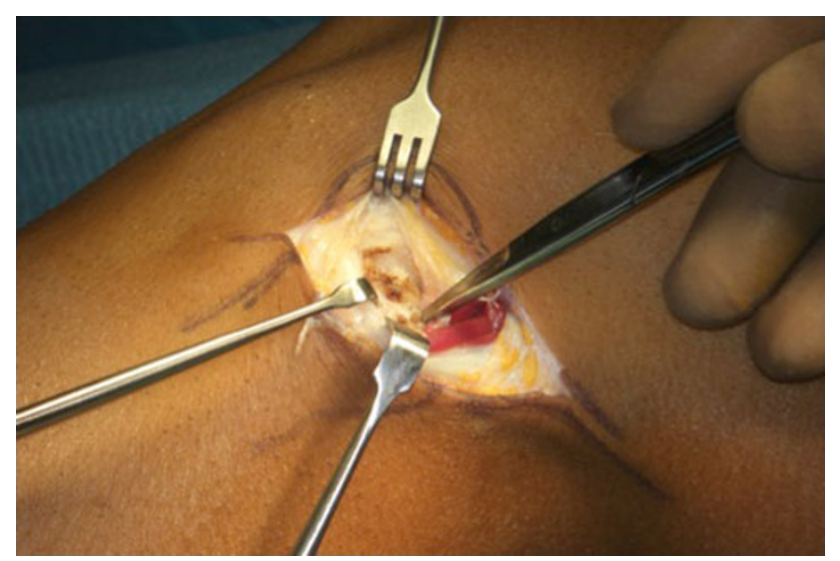

Fig. 4 Partial resection of the fibular head

\section{Discussion}

Snapping syndrome is a common and well-known occurrence in the hip [1], ankle [2], shoulder [3], and elbow [4] but is seldom seen in the knee [5]. Determining the cause of painful snapping on the lateral aspect of the knee can be challenging. The differential diagnosis includes iliotibialband friction syndrome [6], discoid lateral meniscus [7], intra-articular loose body, synovial plicae [8], congenital snapping knee [9], and patellar dysplasia [10]. Subluxation of the gracilis and semitendinous tendons [11], biceps femoris [12-14], and popliteus tendons [15] is another cause.

In recent years, reports on snapping biceps femoris tendon have become more frequent in the literature. Described causes include anomalous insertion of the tendon, trauma, and fibular-head abnormalities such as exostosis. Hernandez et al. [16] and Lokiec et al. [17] reported a case similar to ours of biceps femoris tendon subluxation secondary to anomalous insertion into the anterolateral aspect of the proximal tibia, with sliding over the fibular head; resolution was obtained by tendon reinsertion with transosseous sutures. Another similar case was described by Kristensen et al. [12], but in their case, symptom resolution was achieved by resecting the lateral portion of the fibular head. Bansal et al. [18] described the onset of snapping biceps femoris in a patient following a soccer injury. Bach and Minihane [13] described a prominent fibular head related to snapping-knee syndrome, which they treated successfully with partial fibula-head resection.

In our case, as in the case described by Crow et al. [14], we found no abnormal anatomy in relation to tendon insertion or the fibular head, as evident on imaging studies and under direct visualization during the surgical procedure. Further, only the superior portion of the tendon was subluxated over the fibular head, so the release was limited to this portion, with fibular-head resection restricted to a small section. The success of the procedure was confirmed not only before and after release of the intraoperative tourniquet but with active knee motion. Knee motion was possible at the time of surgery because we combined spinal anesthesia and local laevogyrate anesthetic and opioids, thus blocking pain sensitivity (A $\delta$ and $\mathrm{C}$ fibers) only, leaving motor $(\mathrm{A} \alpha)$, epicritic $(\mathrm{A} \beta)$, and proprioceptive $(\mathrm{A} \gamma)$ fibers intact and sensitive.

In our patient, only one side of the knee was involved. When the symptoms first appeared, he complained only of pain-free snapping during strenuous cycling and running. Only later did the snapping become painful enough to prevent participation in sport. It is not clear what was responsible of the painful snapping. One possibility could be progressive tendon stiffness with the loss of flexibility related with aging or strenuous training; however, physical therapy was ineffective. Another possible cause is the popliteus, as described by Mariani et al. [15], which must be considered in the differential diagnosis. If conservative treatment fails and a surgical procedure is required, the possible presence of tendon or fibular-head abnormality must be investigated. Although symptomatic snapping biceps femoris tendon is uncommon, it must be considered when lateral knee pain is evaluated. Awareness of this condition is mandatory to avoid unnecessary and unsuccessful surgical procedures.

Ethical standards This study was approved by the appropriate ethics committee and performed in accordance with ethical standards laid down in 1964 Declaration of Helsinki. The patient gave his informed consent prior inclusion in the study.

\section{Conflict of interest None.}

Open Access This article is distributed under the terms of the Creative Commons Attribution Noncommercial License which permits any noncommercial use, distribution, and reproduction in any medium, provided the original author(s) and source are credited.

\section{References}

1. Illizaliturri VM Jr, Villalobos FE Jr, Chaidex PA, Valero FS, Aguilera JM (2005) Internal snapping hip syndrome: treatment by endoscopic release of the iliopsoas tendon. Arthroscopy 21:1375-1380

2. Alm A, Lamke LO, Liljedhal SO (1975) Surgical treatment of dislocation of the peroneal tendons. Injury 7:14-19

3. Pearsons TA (1973) The snapping scapula and subscapular exostoses. J Bone Joint Surg Br 55(B):345-349

4. Rolfsen L (1970) Snapping triceps tendon with ulnar neuritis: report on a case. Acta Orthop Scand 41:74-76

5. Bae RK, Know OS (1997) Snapping knee caused by the gracilis and semitendinous tendon: a case report. Bull Hosp Joint Dis 56:177-913

6. Holmes JC, Pruitt AL, Whalen NJ (1993) Iliotibial band syndrome in cyclistis. Am J Sports Med 21:419-424

7. Dickhaut SC, DeLee JC (1982) The discoid lateral meniscus syndrome. J Bone Joint Surg Am 64:1068-1073 
8. Dupont JY (1997) Synovial plicae of the knee. Controversies and review. Clin Sports Med 16:87-122

9. Ferris BD, Jackson AM (1990) Congenital snapping knee. Habitual anterior subluxation of the tibia in extension. $\mathrm{J}$ Bone Joint Surg Br 72:453-456

10. Yoo JH, Kim EH, Ryu HK (2008) Arthroscopic removal of separated bipartite patella causing snapping knee syndrome. Orthopedics 31:717

11. Lyu SR, Wu JJ (1989) Snapping syndrome caused by the semitendinous tendon. A case report. J Bone Joint Surg Am 71:303-305

12. Kristensen G, Nielsen K, Blyme PJH (1989) Snapping knee from biceps femoral tendon. A case report. Acta Orthop Scand 60:621

13. Bach BR, Minihane K (2001) Subluxation biceps femoris tendon: an unusual case of lateral knee pain in a soccer athlete. A case report. Am J Sport Med 29(1):93-95
14. Crow AC, Quach T, McAllister DR (2009) Partial tendon release for treatment of a syntomatic snapping biceps femoris tendon: a case report. Sports Health 1(5):435-437

15. Mariani PP, Mauro CS, Margheritini F (2005) Arthroscopic diagnosis of the snapping popliteus tendon. Case report. Arthroscopy 21:888-892

16. Hernandez JA, Rius M, Noonan KJ (1996) Snapping knee from anomalous biceps femoris tendon insertion: a case report. Iowa Orthop J 16:161-163

17. Lokiec F, Velkes S, Schindler A (1992) The snapping biceps femoris syndrome. Clin Orhop 283:205-206

18. Bansal R, Taylor C, Pimpalnerkar AL (2005) Snapping knee: an unusual biceps femoris tendon injury. Knee 12(6):458-460 